\title{
ENCARGOS DO MINISTÉRIO PÚBLICO NO RAMO CIVIL
}

\author{
Herotides da Silva Lima \\ Desembargador do Tribunal de Justiça de São \\ Paulo, membro da Sociedade Argentina de Bioti- \\ pologia e Eugenésia, de Buenos Aires, e da So- \\ cieté de Legislation Comparée, de Paris.
}

Para salientar a importância social e política do Ministério Público não é mister perfilhar os exagêros daqueles que pretendem elevá-lo à categoria de um poder de Estado, a ser acrescido à tríplice divisão imaginada por Montesquieu, pondo, de parelha com o poder que legisla, com o que governa e com o que julga, o poder que defende a sociedade. Ainda conceituado apenas como uma função, é êle uma das culminantes instituições sociais e políticas do regime, pelos benefícios que sempre trouxe ao Estado e à Sociedade, assim no ramo criminal como no civil, e que, com o andar do tempo e o seu aperfeiçoamento, mais se dilataram. "É maravilhoso exclamam Seidoja, Pisanelli, Mancini e Galdi, nos seus eruditos comentários ao Código do Processo Civil Italiano, que o conceito desta instituição tenha saído de uma idade irregular e bárbara, quasi gerado na desordem. Mas a natureza produz, de quando em quando, homens de gênio que resplandecem como luz inesperada na escuridão do seu tempo e projetam largo facho nos que sucedem. Tais homens valem uma época. Não há quem ignore o que a civilização moderna deve a Carlos Magno". Entre as leis que nos regem - diz Jules Coumoul - umas disciplinam as relações dos particulares, que lhes devem reclamar a aplicação, outras tem como ob- 
jeto a ordem, a paz, a moralidade ou simplesmente a utilidade pública, mas tôdas são revestidas de sanções que não podem e não devem aparecer como vãs ameaças. Numa palavra, é um direito sancionador, que a sociedade deve pôr em movimento através de um dos seus órgãos. Êste órgão é o Ministério Publico, ao qual pertence, conforme a expressão consagrada, por a ação pública em movimento. De outra forma, quando a justiça decidiu, mister se faz que suas decisões não se tornem letra morta: se os indivíduos recusam obediência, o Ministério Público tem o dever de requisitar a fôrça armada para assegurar a execução, seja a pedido dos interessados, seja de ofício, quando as decisões envolvem a proteção ou a utilidade geral".

Os seus representantes sempre tiveram no processo criminal a sua mais saliente atribuição. 0 promotor era o dominus da ação penal, o acusador público, temido pelos criminosos, e cuja eloquência ou dialética podia jogá-los impiedosamente numa Penitenciária, anos seguidos. No tempo em que os debates do Juri ainda não haviam sofrido limitação, os promotores públicos tinham na tribuna do plenário popular o seu mais seguro caminho da glória ou do fracasso, podendo sair para postos mais elevados ou apodrecer na mediocridade dos ambientes estreitos do interior. Ainda hoje, ressalta essa posição, em face da moderna concepção do processo penal, de caráter público, de forma contraditória, indisponível, irretratável, autoritário, marchando contra a vontade do réu, movido inexoràvelmente por uma decisão oficial incontrastável.

As Ordenações, as leis do Império, o Cód. de Processo Criminal de 1830 assinalaram essa feição precípua do Prom. Público, ao qual pertencia pelo art. 37 daquele código denunciar os crimes públicos, acusar os delinqüentes, solicitar a prisão e punição dos criminosos e promover a execução das sentenças e mandados judiciais. Na França, pátria do Ministério Público, dizia Garraud que sua função principal era a de pesquisar e processar os autores de crimes, desempenhando o papel de acusador no processo penal. "C'est en effect - escreveu Jules Coumoul que tão bem se ocupou do Poder Judiciário - c'est en effect, dans l'exercice de la repression, qu'apparait le plus en lumiére son caractère d'homme de la loi et de defenseur des interéts generaux de la sociéte" (J. Coumoul, Traité du Pou- 
voir Jud. p. 386). E um sábio da altitude de Carnelutti afirmou também na atualidade que "o reino do $M$. Público é o processo penal, que é sempre um processo de ação pública (Sistema, 1, pg. 388).

A evolução social logo reclamou o alargamento da ação do Ministério Público nas questões civis, o que tem sido uma constante na vida dessa benemérita instituição, qualificada por Budé, como "a depositária de todos os interêsses do Príncipe e do público, o asilo das leis, a muralha da justiça e da inocência atacadas"; ou segundo Portalis, "bela e grande instituição que preservou os governos modernos dessa multidão de delatores, que era o mal das famílias e do Estado na antiga Roma". (Paula Pessoa, Cód. do Processo Criminal, nota 204).

Em rápido exame que fiz sôbre o papel do Ministério Público, ao comentar o Código de Processo Civil Brasileiro, encareci-lhe a utilidade no meio brasileiro com a invocação dos subsídios da elaboração constitucional de 1934.

Em apôio de uma das emendas sôbre êle, se disse que nos povos de espírito comunário, como o nosso, em que o indivíduo é um fator deficiente como defensor dos interêsses abstratos da coletividade, sobe de ponto a missão de alta inspeção legal e de assistência tutelar atribuida ao M. Público (Cód. do Proc. Civil Brasileiro, do autor, pg. 150).

Essa deficiência cívica do nosso povo, derivada do atraso moral, do analfabetismo, de fatores históricos e hereditários, do isolamento do indivíduo rural, tornaram o brasileiro um indivíduo incapaz de defender jurìdicamente os seus próprios interêsses pessoais, o que já teve como consequência propor-se, há anos, no Congresso Nacional fôsse a menoridade dos analfabetos elevada a 25 anos. Os que já passaram pelo interior do País, ou aí ainda fazem o trânsito obrigatório de qualquer carreira na vida pública, devem ter observado essa falha do nosso homem, que frequentemente recorre aos promotores públicos como elemento de proteção ou orientação.

Quando exercí o cargo de promotor público numa das comarcas do interior de São Paulo, certa ocasião fui procurado por um velho caboclo em luta com um sitiante vizinho por questões de divisas, invocando a interferência da promotoria. Fiz- 
-lhe ver que o caso era para constituição de um advogado, que até mesmo seria dado de graça pelo juiz, se êle não dispusesse de recursos. O caboclo queria insistentemente enquadrar a questão nas minhas atribuições e indagou-me então para que servia o meu cargo. Respondi-lhe numa linguagem simples que tinha como atribuição tratar dos interêsses de órfãos e pessoas assim equiparadas, ao que interrompeu êle: "Pois é seu doutor - eu estou com esta idade mas também sou órfão de pai e mãe..."

Durante muitos anos, foi o promotor público o defensor dos colonos e trabalhadores rurais, como ainda é hoje o defensor público dos operários vítimas de acidente de trabalho, significando com isto que mesmo aos indivíduos maiores o Estado liberaliza, em razão da sua condição de fraqueza econômica, a ação tutelar de funcionários que compõem a organização do Ministério Público, isto apesar de serem indivíduos maiores e jurìdicamente capazes. Essa proteção, independente da idade e da aptidão jurídica do indivíduo, corresponde à moderna tendência do direito, que se orienta num sentido de proteção aos fracos, assim do ponto de vista material, como do simples ponto de vista social ou humano.

Olha êle com simpatia e piedade para os pobres e humildes, que constituem a maioria, o que magistralmente vem exposto no belo livro de G. Ripert - O Regime Democrático e o Direito Civil Moderno (V. também Josserand, Evolutions et Actualités, pg. 159).

Larga é, pois, a ação protetora do Estado através do Ministério Público, colocando humildes e miseráveis ao lado dos incapazes como tais compreendidos os menores, sejam ou não. órfãos, os dementes, pródigos, interditos e ausentes, devendo vigiar o Estado para que todos, como pessoas fracas, não sejam enganados, de tal arte que venham a cair sob as sôpas de caridade pública ou da assistência social. Se a vida social viu a necessidade de criar o advogado para a defesa de interêsses de indivíduos ou de grupos, social e economicamente prósperos, sentiu também a de instituir a advocacia do Ministério Público a favor dos social e economicamente fracassados, sem o que se criariam novas causas de conflitos e revoltas. Aquele que cumpre dignamente as obrigações do emprêgo de curador geral - 
observou o velho praxista Pereira de Carvalho - merece a estima do público e a contemplação do Soberano. Se o interêsse obriga muitas vezes a defender os direitos poderosos, só a virtude pode fazer encarregar da defesa dos desvalidos, de quem nada se espera (Proc. Orfan. parágrafo 14). A ação fiscalizadora e protetora do Ministério Público foi instituída pelas leis reinicolas como necessidade de vigiar o Estado pelos incapazes, notadamente órfãos, pois a experiência tinha demonstrado que ficavam expostos à vingança dos inimigos de seus pais, dos ambiciosos, aventureiros, sôfregos de riquesas fáceis e rápidas, dos auxiliares corruptos do Juizo como oficiais de justiça e avaliadores. Num tempo como o de hoje, em que todos êsses perigos aumentaram enormemente; num tempo cujo carácter nos grandes centros é a ambição, o lucro, o desejo do dinheiro e dos bens materiais, em que o número de causas cresce sempre, muitas vezes sem que as autoridades possam estabelecer contacto com os representantes daqueles protegidos - num tempo dêstes, muito mais grave e importante é a tarefa legal do agente do Ministério Público, ainda que em alguns casos se destaquem cargos especiais de advogados para a assistência judiciária, que é modalidade da assistência social. 0 nosso João Monteiro, ainda hoje insuperável como processualista, inspirado em certos autores italianos, propugnara pela redução, senão supressão das atividades do Ministério Público em matéria civil.

Esse era o pensar de Matirollo (Diritto Giud. Civile 1, pgs., 475 e 476) e assim foi também a conclusão do Congresso Jurídico de Roma, em 1872. Afastado, neste ponto, das realidades nacionais e das próprias razões históricas, dizia o grande processualista que "já não há quem não clame contra a intervenção do Ministério Público fora do círculo em que a sua ação é reclamada pelos verdadeiros incapazes e indefesos, e a tríplice maneira pela qual se manifesta a sua intervenção isto é, ou por via de ação ou por via de requisição ou por intermediário de certas pessoas físicas ou jurídicas".

Sem embargo dessa opinião de tamanho prestígio, penso que a ação civil do Ministério Público tende a ampliar-se, pelo menos no ambiente brasileiro, com as suas peculiaridades sociais. Não foi sem uma alta razão de interêsse público que 0 espírito francês, com a sua sabedoria e o seu atilamento, tenđo 
instituido o Ministério Público extendeu o seu campo de ação aos negócios civis, conforme lembra o professor Bellot, na exposição de motivos ao Código de Processo Civil do Cantão de Genebra (pg. 38).

Estou de preferência com a opinião do notável Gargiulo quando afirma "noi riconosciamo nel publico Ministero, non una solitaria opinione personale, non um elemento che arrechi disquilibrio tra le parti, non una indebita intrusione del potere esecutivo, ma un ente, un instituto, il quale costantemente, imperturbabilmente si mantiene nelle elevate sfere del l'interesse sociale e della retta esecuzione della legge. Onde è per noi desiderabile che sià alongata di nuovo la sfera del suo intervento nelle cause civili, ed ordinato in maniera che riacquisti l'antico splendore, autoritá, prestigio e fiducia" (Diritto Giudiziario, pg. 62).

No processo civil brasileiro o órgão do Ministério Público tem intervenção obrigatória nos processos em que há interêsses de incapazes, que, como se disse, abrangem os menores, órfãos ou não, ausentes, dementes, pródigos, interditos, sob pena de nulidade; é citado como as partes, é apregoado nas audiências quando interveio inicialmente e toma parte nos debates; requer inventários, quando haja incapazes, impugna avaliações, opina sôbre testamentos, solicita arrecadação de bens de ausentes e de defuntos em caso de herança jacente, opina sôbre o registro civil com os seus importantes atos relativos ao nascimento, ao casamento e ao óbito; requer interdições e a remoção de tutores e curadores, manifesta-se sôbre emancipações e outorga judicial de consentimento, sôbre venda de bens de órfãos e incapazes, vigia pela instituição e existência das fundações, promove a dissolução de sociedades de fins anti-sociais, suscita conflitos de jurisdição, tendo mesmo o encargo de promover a aplicação de certas penas aos juizes, como no caso do art. 228 do Cód. Civil. Pode exigir o cumprimento de doações feitas no interêsse geral, requer a inscrição de hipoteca legal dos incapazes e a favor da Fazenda Pública sôbre os imóveis do delinqüente; pode reclamar medidas contra os próprios pais que abusam do pátrio poder, arruinando os bens dos filhos; pode argüir nulidades do art. 145 do Cód. Civil. Inúmeras outras funções na ordem civil podem ser e o são, cometidas aos mem- 
bros do Ministério Público dos Estados, pois que a Constituição Federal declara no art. 126, parágrafo único, e 201 parágrafo segundo, que a lei pode encarregá-los de representar a União nas comarcas do interior.

Recentemente, em processo cuja nulidade foi solertemente pedida pela Procuradoria Geral da Justiça por se ter omitido a intervenção do Ministério Público, em primeira instância, manifestei-me apoiando êsse ponto de vista. Mesmo tendo o menor representante, essa representação completa-se obrigatòriamente com a presença do órgão da Curadoria, nos termos e sob as penas dos arts. $80, \S 2$ e 84 do Cód. de Processo Civil, ladeando-se a nulidade, se o resultado fôr favorável ao menor.

A intervenção do Ministério Público não constitui simples recomendação, uma formalidade burocrática, de resultado inocuo, uma superfluidade, destinada a justificar acidentalmente a existência de tais agentes do Poder Público, mas uma necessidade ditada pela ordem pública, afim de evitar que fiquem irremediavelmente comprometidos os direitos patrimoniais $\mathrm{e}$ morais dos menores, pela velhacaria de seus representantes ou de terceiros ou mesmo pela boa fé dos Juizes. A experiência, que é fonte de sabedoria, tem ensinado que aqueles direitos correm perigo quando fraqueja ou desaparece a vigilância do Ministério Público. É então que corvejam em tôrno dos bens dos menores o enxame dos abutres, a ronda dos aventureiros impiedosos, ávidos de ganhos fáceis, ainda que ilícitos, arruinando criaturas que devem ser poupadas à miséria e à desgraça. Só o Ministério Público pode apoiar na esfera judicial civil a sorte de tais pessoas, amparando também como diz Calamandrei os direitos subjetivos do Estado, envolvido com o daquelas pessoas.

Em outros casos forenses assim me manifestei, inclinando-me pela nulidade dos atos feitos com despreso da interferência do Ministério Público. Essa também tem sido a melhor jurisprudência (Rev. dos Tribunais. - 170-340 - 140212 - 143-704 - 156-621 - 159-212 - 162-141 - 167-173 - 179-640 171-187 - 172-180 - 173-692 - 177-678 - 183-709 - 185-779).

Larga e benéfica é a influência do Ministério Público na ordem civil e não menos larga na ordem política, notadamente, depois do advento da Constituição Federal de 1946, em que o 
Procurador Geral da República ficou investido da grave iniciativa de enquadrar os Estados nos princípios daquela Constituição.

Pode-se dizer do Ministério Público como se disse do próprio direito de que êle é órgão ativo: acompanha o homem desde antes do seu nascimento, vigiando pelos interêsses do nascituro, até depois de morto, velando pela vontade do testador.

Os seus curadores com todos êsses poderes de iniciativa e de contrôle no processo civil, não podia a lei processual, sem ser contraditória ou absurda, reduzir ao papel nulo ou apagado, que representariam, com a interpretação de alguns sôbre a sua posição no campo do processo civil. Cometeria assim o legislador o despropositado ilogismo de dar em teoria uma tal proeminência ao Ministério Público e retirar-lhe na prática os meios de chegar aos fins, quando é sabido, como ensina Rui Barbosa que - "em se exercendo um fim, os meios para êle estão autorizados" (Const. Fed. Vol. I, pg. 225). Como poderá o representante do Ministério Público exercitar a fiscalização civil que a lei lhe traçou, e a que não pode renunciar, senão excepcionalmente, sem recorrer a todos os meios que a lei previu, entre os quais aparecem como dos mais importantes o direito de recorrer?

Apegam-se alguns intérpretes ao enunciado do art. 814 do Código do Processo Civil que só às partes concede aquele direito, cabível ao Ministério Público apenas quando expresso em lei. Segundo essa exegese, sòmente quando a lei fôr explícita quanto ao recurso do Ministério Público, êste poderá manifestá-lo. Em primeiro lugar, o Código de Processo só contém, salvo equívoco meu, um caso único em que se menciona o direito do Ministério Público recorrer, e é o do art. 610, aliás inútil, pois o Ministério Público sempre poderá recorrer: de fato pode recorrer quando promover a interdição; e pode recorrer quando não a promover, pois neste caso é o defensor do suposto incapaz (Cód. Civil, art. 449), de maneira que afora êsse caso e poucos outros de iniciativa do Ministério Público (arts. 30, parágrafo único, 145,208 , II -228 , único - 394, 840, I - 842, II - 1180, único, do Código Civil) êste não terá recursos, apesar da enorme lista de suas atribuições! 
Sempre me insurgi contra essa interpretação, principalmente tendo em vista o disposto no art. 84 do Código de Processo Civil que declara nulos os atos realisados sem intervenção do órgão do Ministério Público, intervenção ditada por motivo de ordem pública, mas que singularmente aqueles funcionários jamais poderiam alegar perante a Segunda Instância porque não poderiam recorrer!

$\mathrm{Na}$ "Revista dos Tribunais" (Vol. 169, pg. 209) manifestei essa divergência, em que sempre tenho insistido. Disse então que a lei obriga o agente do Ministério Público a intervir como fiscal de sua execução e defensor de interêsses de incapazes sob pena de nulidade; dá-Ihe iniciativas para opinar e requerer medidas de interêsse das pessoas a que se estende a sua proteção; não podia, sem ser absurda, tolher-lhe a atividade, precisamente, no momento mais grave, aquele em que já existe uma decisão prejudicial àquelas pessoas, atingindo diretamente interêsses morais e materiais da mais alta relevância. Tais decisões, recorríveis para todos os litigantes ou partes, passariam a ser irrecorríveis para as pessoas a quem a lei quiz especialmente proteger. Sim, porque quando um tutor requeresse medida prejudicial, e esta fôsse deferida pelo magistrado, o tutor jamais recorreria, e a medida passaria a produzir todos os efeitos sem que o Ministério Público pudesse fazê-la reexaminar pela Segunda Instância. Chegar-se-ia mesmo à situação de ver-se repelida a própria intervenção do Ministério Público, porque negada a sua intervenção, parcial ou totalmente, não poderia êle alegá-la em recurso, porque lhe seria defeso recorrer. $\mathrm{E}$ ainda que admitida a intervenção, mais tarde não poderia alegar um êrro mais perigoso, o gravame da decisão! Teria assim o Ministério Público uma atitude platônica em primeira instância, uma fiscalização parcial ou pela metade, a bem dizer, inútil, porque só se exerceria quando os representantes dos incapazes ficassem vencidos e recorressem.

O Ministério Público, ao recorrer não o faz como parte, mas como um representante especial do Estado, zelando pelos que êste colocou sob sua vigilância e pelos interêsses de acatamento ao direito objetivo. 
Disse muito bem o ilustre sr. Desembargador João Soares, do Tribunal do Rio Grande do Sul, que "embora a legislação processual não declare expressamente que ao Ministério Público é lícito interpor qualquer recurso de sentenças prolatadas em feitos em que houver interêsses de incapazes, êsse direito decorre, por fôrça de compreensão. Se a sua intervenção é obrigatória, sob pena de nulidade dos atos realizados, com preterição dessa formalidade, seria contraditório impôr-se ao Ministério Público intervir no processo, e, ao mesmo tempo, retirar-lhe os meios legais em defesa dos interêsses que está acautelando, inclusive o de recorrer da sentença, se esta, por acaso, contrariar êsses mesmos interêsses" (Rev. dos Tribunais 160804).

Se o simples interêsse privado da parte ou de terceiro pode fundamentar o recurso, como não o poderá o interêsse público de que o Curador é o fiscal? Que lógica poderia haver numa lei que nomeasse um funcionário para fiscalizar a ação dos particulares e dos juizes e os mandasse calar quando precisassem atuar e demonstrar que tais interêsses foram lesados e que a lei fôra violada? Negada que seja ao Ministério Público a qualidade de parte principal, porque não teve iniciativa em reclamar a prestação jurisdicional, será êle parte acidental na lide para a qual foi necessàriamente chamado e em que discutiu o fato e sustentou o direito, pois para isto .o Código de Processo the concede oportunidades (arts. 21, 80, parágrafo $2 .^{\circ}, 264$, 269, 294, I). Como bem acentúa Calamandrei, o Ministério Público tem perante os juizes a posição de sujeito agente, estimulador da função judicante, o que no processo é tìpicamente próprio das partes. No processo civil, ainda que o Ministério Público seja regulado sob título diverso daquele que estatui sôbre as partes, as suas atribuições, seja por via de ação seja por via de intervenção, são idênticas às das próprias partes (Istituzioni di D. Processuale Civile - Vol. 2, pg. 278).

O notável Gargiulo já havia assinalado essa condição de parte no Ministério Público, seja como agente da ação, seja intervindo com simples pareceres ou conclusões. "Quanto alle attribusioni civile, il pubblico Ministero esercita un doppio of- 
ficio, l'uno di parte principale, l'altro di parte aggiunta; nel primo caso agisce da attore, qual rappresantante della Societá e nel cui nome ed interessi promuovo l'azione; nel secondo caso dà il suo parere e conclude" (ob. citada, pg. 62).

$\mathrm{E}$ depois é preciso ter-se em vista que a ingerência do $\mathrm{Mi}$ nistério Público pode trazer argumentos novos, de grande valor, pela sua imparcialidade, mas que seriam inteiramente despresados, permanecendo nos autos como trabalho inútil. No meu fraco entendimento, ainda quando não seja tìpicamente parte no processo, o Curador funciona como um agente do Estado para velar pela observância das leis, a favor do interêsse público, cabendo-lhe, portanto, o direito de recorrer, tanto mais que pleiteia objetivamente pelos interêsses de pessoas ou de instituições, mas pelo o resguardo de interêsses superiores que se impõem a tudo e a todos.

Os ilustres comentadores do Código Italiano - Pisanelli, - Scioloja, Mancini e Galdi, em que parecem ter-se inspirado alguns opositores nossos, também entenderam que o Ministério Público não podia recorrer, porque a reforma da sentença devia fazer-se, conforme o Código, por solicitação das partes e portanto, em seu benefício (Comentário, vol. 4, pg. 79). 0 argumento não procede, porque ou o Ministério Público tomou a iniciativa e assim pode como qualquer parte pleitear a reforma da sentença, ou apareceu na qualidade de agente da lei e terá o interêsse político da sua defesa e boa execução. 0 dec. lei 9608 , de 19-8-946, que organizou o Ministério Público Federal, já dispôs, corretamente, que aos Procuradores da República cabe interpor e arrazoar os recursos legais de decisões e sentenças proferidas nos processos cíveis ou administrativos em que devam funcionar ( $\operatorname{art} .11, \mathrm{n} .^{\circ} \mathrm{X}$ ) ; e como os Promotores Públicos tem, em cada processo a seu cargo, as mesmas atribuições, segue-se que podem interpor recursos, independente da posição de parte.

A vista do que venho de expôr, concluo que a ação fiscalizadora do Ministério Público no ramo civil, como a previu o Código de Processo Civil Brasileiro, é da mais alta conveniência pública e indisponível; essa intervenção, por isto mesmo, 
tem sido alargada, salvo quando o Estado entendeu de destacar funcionários para acudirem fora do Ministério Público, interêsses de pessoas humildes, economicamente fracas ou indefesas, como no caso da justiça gratuita e da assistência social. A ação do Ministério Público, sempre que a lei a reclame, não deve ser coartada, inutilizada, reduzida, mas equiparada à das partes, e assim tem êle o direito de interpor recursos, tôda vez que tiver o dever de intervir.

0 art. 814 do Código de Processo sómente quis significar que fóra de tais casos, quando a intromissão processual do Ministério Público ocorreu facultativamente, por simples solicitação do Juiz, quando dela podia prescindir, ou havendo dúvida, aí não poderá êle recorrer, senão quando a lei expressamente o permitir. 